\title{
Applying Mind Map in Teaching History in Primary Schools - Case Study of Dak Lak Province, Vietnam
}

\author{
Thi Thuy An Le, Thi Anh Mai Nguyen, Thi Tam Bui, Thi Diu Luu*, Thi Kieu Loan Dinh
}

\author{
Tay Nguyen University, Vietnam \\ *Email: 1tdiu@ttn.edu.vn \\ Submitted: 25 September 2020. Revised: 13 November 2020. Accepted: 13 February 2021
}

\begin{abstract}
This article discusses the role and meaning of the application mind map in teaching history in primary schools in Vietnam. In doing so, this paper studies requirements, designing process and then proposes satisfactory methods to apply mind map in teaching history suitably in Vietnamese education environment. By doing so, the research partly improves the quality and effectiveness of historical lessons in primary schools (class 4 and 5) in to obtain a higher aim of developing students' abilities. In this paper, the author applies mixed researching methods including analyzing data, pedagogical viewing, surveying, and pedagogical experiment and then evaluating educational experience. The research's results support previous studies about the role and effectiveness of using mind map in teaching in general and in teaching history in particular. The author also suggests that in to promote the success of mind map in education, teachers need to mix several teaching methods and technics.
\end{abstract}

Key words: mind map, teaching history, primary school

How to Cite: Le, T. T. A., Nguyen, T. A. M., Bui, T. T., Luu, T. D., \& Dinh, T. K. L. (2021). Applying Mind Map in Teaching History in Primary Schools - Case Study of Dak Lak Province, Vietnam. Journal of Nonformal Education, 7(1), 119-126.

DOI: http://dx.doi.org/10.15294/jne.v7i1.29278

\section{INTRODUCTION}

In 2013, Vietnamese government ratified the resolution of innovating Vietnamese education essentially and comprehensively. Requirements for increase teaching quality are necessary and compulsory, in which teachers need to focus on students' independence, activeness, creativeness (Central Committee of the Communist Party of Vietnam, 2013). Regarding to subject of history, it is a pressing requirement in both theory and practice. This subject has been considered as "supplemental subject" in schools and Vietnamese education, and teachers mostly apply one-way teaching method. As a result, marks of Vietnamese students in History in many years sound arming. For example, in 2011 there were thousands of zero-point marks of History in the National Examination. In 2017, the first- time historical test was conducted by multiple-choice questions and there were more than hundreds of ten-point marks. However, in the National Examination in 2018, more than 83\% of test was under the average mark (under five-point), and in 2020 the result is $46,95 \%$ under the average mark.

History owns specific characteristics in comparison with other subjects. Students cannot view or observe directly historical events, witnesses (for example, that the United States detonated two nuclear bombs over Japan in 1945, that the independent wars of Vietnamese people in the past). The "past" characteristics of History can be seen as one of difficulties and barriers during the learning progress, especially with primary students who cannot pay more attention to studying. A general rule in learning history is that it starts from observing events and pictures and then students can create and develop their imaginations. Accordingly, in teaching history in primary schools, that exploiting diversified pictures and color of history will create high-valuable information which helps pupils to receive knowledge with different and interesting perspectives which is not imitative. All those things create a new amenity for students during their learning process in the class and then they can find more information and knowledge with the instruction of teacher actively. Beyond that, students can remember historical knowledge and develop their abilities, creativeness.

History includes massive information of human in the world from the ancient period to present day; in which students have also focus on Vietnamese history. However, historical knowledge has its own specific characteristic - all events and phenomenon have a closed connection, and there is no isolated historical event. All things are reasons for other events and of course they are the results of previous historical events. Therefore, in teaching history, the most important task is to help students to clarify logical relationship, causality between historical events.

That applying mind map in teaching history helps not only students to clarify, generalize historical knowledge in order to view and evaluate all historical events in a unified relationship, and in the developing progress but also to remember historical pictures, phenomenon in the network and chain longer, more 
carefully and precisely. As a result, exploiting mind map in teaching and learning history is necessary to partly contribute to improve the quality of education, and then meet the demand of Vietnamese requirements of innovation in the modern situation.

Mind map (or mental map, concept map) and using mind map have a long history but they became popular in the late 1960s with research of Tony Buzan and his colleagues relating to study and renaissance. They are visual tools allowing learners to discover basically information, the relationship between old and new information, and ways of organizing the ability of remembrance and creating ideas which improve educational quality (Buzan, 1993, 2011).

Mind map is exploiting in many subjects, from daily life to academic jobs. Regarding to education, mind map has been used in all training levels and subjects. Tanriseven (2014) argues that using mind map is good in training teachers while Dushkova \& Tsankov (2015) focus on using information technology with software of World, PowerPoint, Imindmap 8 to build mind map for students of Language and History. Buran \& Filyukov (2015) pay attention to technique of creating mind map in learning language. Using mind map in teaching in high school is also confirmed to help students to have dynamic on learning (Stankovic, Besic, Papic, \& Aleksic, 2011), or it is actively learning tool (Willis \& Miertschin, 2006). Other scholars apply mind map in different subjects of Physics ((Li, Tran, \& Le, 2016), Geography (Nguyen \& Pham, 2018; Sari, Sumarmi, Utomo, \& Astina, 2019), Language (Tran, 2020). Dhiyauddin, Ahmad,

\section{METHODS}

The authors raise some several researching questions during the process of writing this article. Why do we need using mind map in teaching history in primary schools? How to exploit mind map in teaching history? We research and apply theories from documents of Psychology, Pedagogy, Theory of modern teaching, Methodology and methods of teaching History; Vietnamese Communist Party and Vietnamese government's opinions about educational innovation, Ministry of Education and Training's changes about curriculum, examination, especially about program of history subject in primary schools; and other materials of theories and practices of using mind map.

The authors also study the practice of using mind map in teaching history in some primary schools in Vietnam via observing, interviewing to have particular information about the situation of using this tool to propose useful and effective methods of using mind map in teaching history. In detail, we issue 40 surveys for 40 teachers teaching class 4 and 5 in three
Ismail, \& Diah (2018) argue that history is a boring subject and students always avoid from learning it. That applying some software such as Adobe Photoshop, Adobe Illustrator and Unity is useful to create mind map; and that using diversified colors and pictures, shapes has high meaning in teaching and learning history, in which including Islamic history. Dris \& Kamaruddin (2018) demonstrate that using mind map can improve students' knowledge about historical identification, information, events; and in some cases, it can be used as a method of self-study.

In primary school, mind map is applied in different subjects and its effectiveness is evaluated in many international and Vietnamese research. For example, (Sari, Sumarmi, Utomo, \& Astina, 2019), (Rudnik, 2014), (Tran \& Dang, 2011) focus on using mind map in teaching primary school while (Le \& Nguyen, 2016), (Phan, 2014) argue its role in teaching by telling stories.

That using mind map is an effective and optimal method of many subjects, many aspects of Vietnamese education. However, in the fact of Vietnamese education in general and teaching history in primary school in particular, most teachers apply mind map as a visual tool to support the teaching and learning process rather than exploiting it as a tool in active teaching. Especially, the progress of design and use mind map is often one-way as teachers are creators and users under their own experience while students receive mind map's effectiveness negatively and have little knowledge about shape and characteristic of mind map.

primary schools namely To Hieu, Le Hong Phong, Vo Thi Sau in Buon Ma Thuot, Dak Lak province, Vietnam. Survey's results show that $0 \%$ teacher often use mind map in teaching history; 5\% teachers sometimes use this tool; 95\% teachers has never applied it. It means that mind map is rarely applied by teachers in Dak Lak, Vietnam. This result is equivalent with the result of our observation. From then, we interview teachers deeply. The response is that teachers do not use mind map as it takes a lot of time and preparation. Moreover, teachers in primary schools mostly focus on Mathematics and Vietnamese. History is still "supplemental subject" and teachers' methods are presenting, and students record their voice. Some other teachers respond that because most pupils in Dak Lak belonged to ethnic minorities and they are difficult in using Vietnamese, they cannot use mind map in learning. However, almost of them $(98,4 \%)$ agree that using mental map in teaching not only helps students to remember knowledge but also develop their creativeness, ability. Therefore, using concept map in teaching history is necessary and compulsory. 
Moreover, we study on 160 pupils of the three above primary schools. $71 \%$ students answer that History is a major subject, $15,9 \%$ students think that it is very essential while only $13,1 \%$ pupils consider History as a supplemental subject with little influence. The result of surveying students shows that using mind map in learning History is quite rare and they still learn by traditional way of listening teacher's talks and then record knowledge in their papers.

\section{RESULTS AND DISCUSSION}

\section{Theories about mind map \\ Definition of mind map}

Mind map is a tool to organize people' thinking which is studied, established and expanded by Tony Buzan - British expert on research about brain's activities (Buzan \& Buzan, 2006). Mind map or mental map, concept map is a way of writing, painting and mapping knowledge to discover deeply people' ideas, and then generalize it in a unified theme or a line-knowledge by using diversified pictures, maps, shapes, lines, colors, and hand-writing.

That using key words, number, colors, and pictures creates a large influence in helping students' learning as it requires students' both left and right hemispheres to work together. This mixture increases the co-operation between the left and right hemispheres and accordingly to develop learners' intelligence, creativeness.

\section{Structure of mind map}

At the center of mental map is a key or central picture/word to generalize the subject's theme. The firstlevel agents are around the central theme to make its meaning, definition. The second-level branches are supported for the first-level agents to make them more detail. Those divisions are applied continuously to specify the ideas and opinions of the central theme. Farer braches provide more detail information. As such, mind map is a general picture, a network with a close connection between different levels to present form and content of specific knowledge (Buzan \& Buzan, 2006).

\section{Role, meaning of applying mind map in teaching history in primary schools}

That applying mind map will help to increase teaching quality. By using mental map, teachers seem to have a unified and precise direction and aim for the subject. This helps teachers to present their
Due to this learning method, students are scare and uninterested in History. As we introduce and apply mind map in teaching History, there is a noticeable change. 97\% pupils feel to love History and want to study History by mental map. As such, from both theory and this practice, we propose suitable methods to teach and learn History by mind map to serve the real requirement of Vietnamese education.

knowledge clearly, precisely and then their discussions, arguments are interesting and attractive. Moreover, using concept map helps teachers to clarify and focus on main and key contents and avoid supplemental and sometimes unnecessary information in preparing and teaching. In History, because the way of presenting lessons, knowledge and experience in the textbook are quite difficult to understand, that applying concept map can help teachers to prevent the above limitation.

Mind map can be seen as a compass for students to help them to clarify fundamental knowledge to write and remember. By using mental map, students understand not only specific knowledge but also the connection and link between the knowledge. In learning History, students only understand lessons as they recognize knowledge in a system, and then they can generalize and apply experienced lessons during the progress of using visual tools. Clearer, more detail and precise mind map, more effective lessons students can obtain. With an effective concept map, students can create systematic and logical thinking, and then they can remember longer, and apply studied knowledge in their daily life. By using mental map, students know to exploit textbook more effectively and smartly. Moreover, as teachers instruct students to create mind map, they gradually build fundamental skills of self-study. As students can selfbuild a concept map, it means that they understand the content of lesson.

In brief, using mind map in teaching History in primary school has essential meaning as it is a specific method to establish students' knowledge.

\section{Process of creating mind map for History-lessons}

From the above definition of mind map and previous studies about the way to create a satisfactory concept map, we design a process of establishing mind map for History-lessons with 4 main steps as such: 


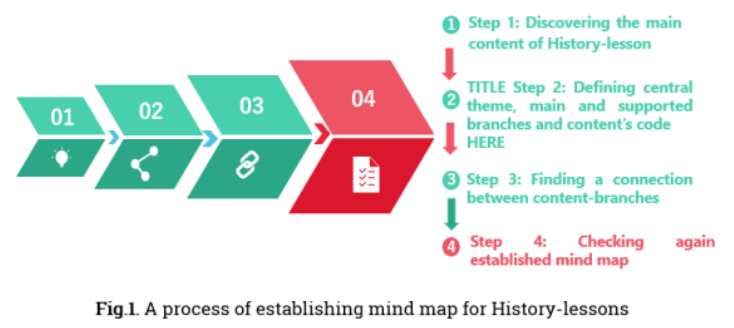

Step 1: Discovering the main content of Historylesson

This is the first teachers' activity as they prepare to create a mind map for lesson' content. By discovering main contents of history-lesson, teachers can clarify its key knowledge with different levels. With this activity, teachers understand not only several perspectives, viewpoints of one historical event and phenomenon but also its logic, characteristic.

Based on clarifying key contents of lesson in mind map, teachers make a list of essential knowledge. It is main, basic, and central content of the lesson and it is compulsory to remember. That establishing a list of content is based on the aim of lesson. It is the first, compulsory and principal activity as discovering essential knowledge is the first factor to create central theme, and then different branches of mind map.

Step 2: Defining central theme, main and supported branches and content's code

Central theme reflects teaching theme and content, and it is located at the heart of the paper or picture. That clarifying number of main and supported branches of mind map is based on both knowledgecontent in the lesson and teachers' pedagogic targets. Number of branches in mind map therefore has both objectivity and subjectivity. Because mind map has general and systematic characteristic, we cannot fill all sentences or words, pictures of lessons' contents. Coding knowledge or restraining content is therefore necessary to have short and satisfactory visual and easy words and pictures but they can include large information. Clarifying main and supported branches is an important and main step during the process of establishing concept map. As creating mind map of for History-content lesson, teachers must focus on the order of lesson to provide satisfactory knowledge for students.

Step 3: Finding a connection between contentbranches

In step 2, mind map is almost done with key content of History-lesson. However, if the map is stopped there, it is only a map to illustrate knowledge, and it cannot create a logic and link between historical events and phenomenon. Therefore, in this step, teachers need to instruct students to find a connection between different contents based on several branches of mind map to make clearer contents of the central theme.

Step 4: Checking again established mind map
Into secure mind map' logic, precision, and sense, teachers need to examine its potential. At this step, teachers instruct students to use mental map and present, discuss it to check the quality of mind map and the ability to help students to understand lesson.

\section{Requirements of using mind map in teaching history in primary schools}

Firstly, maintaining and securing the suitability of using mind map. The suitability is presented by using on time, on right place and teachers cannot abuse it. That clarifying how, when and where to use mind map is based on the aim of historical lessons, program's contents, textbook, and of course a specific knowledge. From then, they can choose types of mental map, its forms, time and duration to use mind map.

Secondly, securing that mind map fits students' ability perfectly. It means that mind map needs to be beautiful, scientific, creative, and easy to understand. This requires teachers not only illustrate historical knowledge in mind map but also encourage and create good condition for students to learn, study and then complete mind map after reading textbooks.

Thirdly, developing students' activeness in learning history during as they use mind map. This requirement is presented by students' behavior of learning, how interesting and enthusiastic they are during the learning progress. Students desire to find more knowledge to complete mind map, research a connection between different contents and knowledge.

Four, mixing mind map with other teaching methods and technics. Abusing mind map or considering it as a master key to replace all other teaching methods is misunderstanding. Several teaching methods suitable with mind map are presenting, problem-solving method, discussion, debate. Modern technics can apply in using mind map are software, IT, Power Point, IMindMap, Mindjet Manager.

\section{Exploiting mind map in teaching history in prima- ry schools \\ Levels of using mind map in teaching history}

That applying mind map in teaching History is quite different from traditional teaching and learning methods. As a result, in the first times, students feel surprised and difficult to understand the meaning and structure of mind map or how to exploit it in learning. Teachers therefore need to instruct, train them gradually with different lessons to increase students' knowledge about this type of map. Via researching theories and practice of using mind map in teaching History in some primary schools in Vietnam, we suggest three levels of using mind map. 


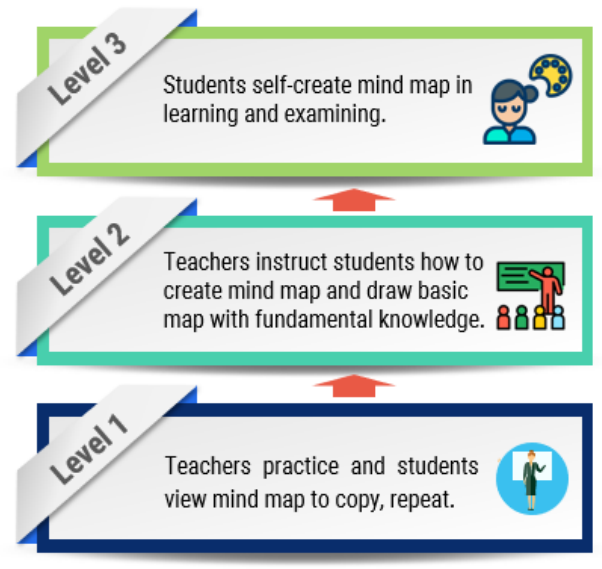

Fig.2: Levels of using mind map in teaching history

At level 1, teachers use mind map as a tool to transfer their knowledge to students. Teachers selfbuild all concept maps to illustrate lessons' content. Students only receive new knowledge from pictures, words, and graphs in mind map. However, to make this level better, teachers can help students to create their skills of self-read and translate mind map. In which, reading mind map is to understand the content inside mind map or which is coded by specific language based on researching central theme, main and supported branches. Translating mind map is that students re-write lessons' contents in mind map by their ideas. As such, level 1 is the lowest place of using mental map. This is applied as students start to learn with graph and map in class. As a result, effect of this level is quite low.

At level 2, students self-study lessons' contents in textbooks, references to have knowledge to complete missing and vacant mind maps. This can be seen as the second and higher level. In this place, mind map can be seen as a tool to help teachers to organize students in studying and researching. In doing so, teachers prepare several questions, instructions to help students to discover and research textbook and other materials to fill mind maps.

At level 3, students self-create their mind map of lessons' contents. In this place, the role of teacher is to organize, instruct, control, manage, and adjust students' progress of creating concept map. It therefore, encourages and increases students' activeness, independence, creativeness to research, study and

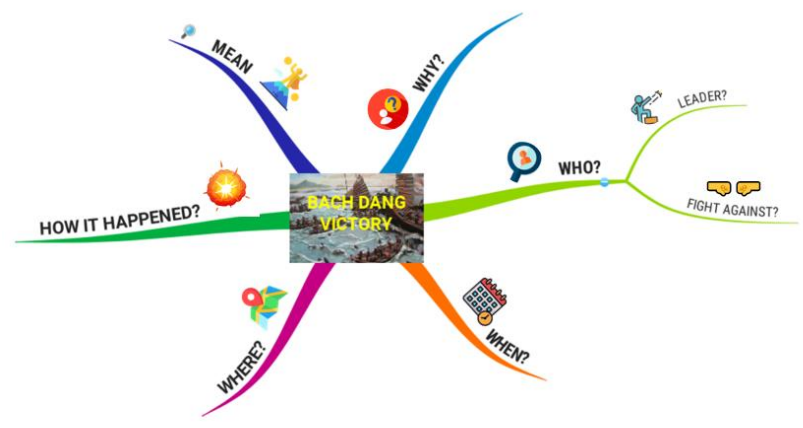

Fig.3. Mind Map about Bach Dang victory build mind map as their own imagination and understanding. By doing so, teachers not only examine students' ability of understanding, their creativeness, and independence but also help them to establish a practice-skills. This level is applied in general lessons, homework, or during the examination. Sometimes, it is used to create a new knowledge.

\section{Applying mind map in transferring new knowledge}

Researching new knowledge is the main lesson the program of History with more than $80 \%$ time (Phan, Trinh \& Nguyen, 2009). This type of lesson provides students new information and helps them to know and then understand new knowledge. Teachers can use mind map in teaching this type of lessons in all steps from introducing, providing new knowledge, reinforcing lessons' contents and even in homework. However, to use mind map suitably, teachers need to consider lessons' targets, their content and pedagogical aims. To have a good lesson, teachers need to mix mind map with other teaching methods, especially problem-solving teaching, using visual tools as Power Point, maps.

* Using mind map to create a problem-having situation

During the process of teaching History, as teachers use a simple introduction, it is hard to attract students and they do not focus on the lesson' content from the first period. Rather than using traditional introduction, mind map is an optional choice to create a problem-having situation.

For example, as teaching Lesson 5: The Bach Dang victory of Ngo Quyen (938) in History for class 4 , teachers can prepare and practice as bellow to create a problem-having situation:

1. Can you find some key words relating to Bach Dang victory?

2. Teachers show mind map to introduce new lessons: the Bach Dang victory ended more than 1000 years of Vietnam under the Chinese control. In to find reasons, contents, result and meaning of this victory, we will discover information and answer the following questions to fulfill this mind map

As such, by using mind map to introduce and create a problem-having situation, teachers instruct and attract students to new lesson with high attention from the early time. From the above simple mind map, teachers can direct students in central and key theme of the lesson.

* Using mind map to teach new content

That teaching new knowledge often occupies around $70 \%$ timing of the lesson. It is also the most important and decisive activity towards lesson' effect. To achieve an effective lesson, teachers need to elicit students' demand and interest of learning. By doing 
so, teachers can avoid the simple, boring teaching learning progress.

In to apply mind map in teaching new knowledge, teachers code knowledge in map to replace a traditional method. However, students still listen and follow teachers' instructions to record new knowledge by their own words. In which, teachers' role is to instruct students to clarify central theme, main and supplemental branches of mind map. This method should mix with normal map, presenting, discussion, and explanation.

For example, teaching lesson 19: Literature and Science in Later Le dynasty (History in class 4), teachers complete mind map during the teaching process:

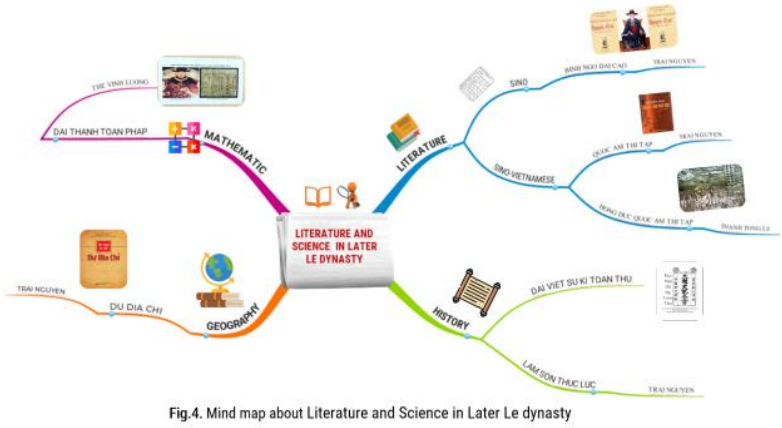

That using mind map is to help students to understand essential historical events and phenomenon deeply. It is a principal brick to build historical knowledge and understanding with meaningful symbols. That students understand historical events is fundamental to create historical symbol and then establish historical definitions.

\section{Using mind map to reinforce lesson' contents}

Besides applying mind map in introducing and teaching new knowledge, this activity can be used to reinforce content in each part of lesson or at the end

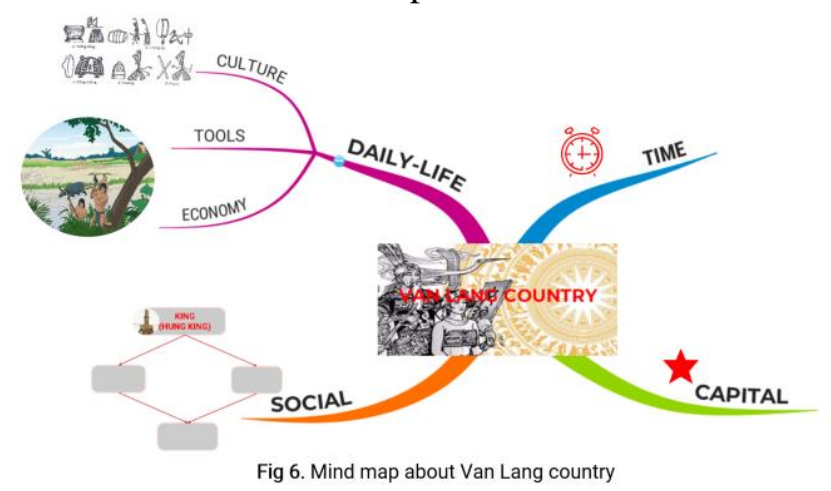

From the above concept map, teachers can expand their questions such as requiring students to evaluate citizen's daily life, to find types of culture maintaining until now.

As applying mind map to build homework for students, teachers need to focus on the diversion and abundance of mind maps. Teachers can apply mental map for homework with different levels: of the class. During the process of teaching new knowledge, after each unity of knowledge, each main and supplemental branch is partly completed. Therefore, teachers can use that type of mental map together with presentation to reinforce lesson's contents in each part.

Moreover, before or after teaching History program in class 5 , teachers can apply a mind map to systematize the whole content to direct or conclude students'

knowledge.

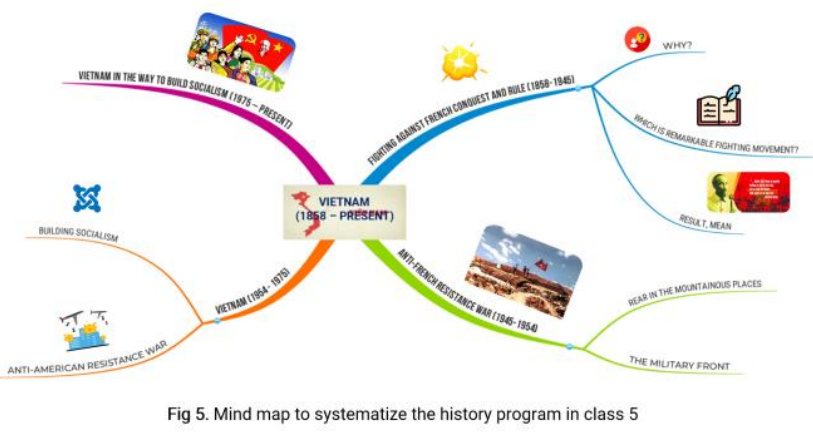

However, as concluding students' knowledge, teachers need to instruct students to finish mind map by filling lesson' content in supplemental branches. Using mind map to examine, evaluate students' results in learning history

Examining students' results in learning history is an essential activity. This step is one of activity to contribute to Vietnamese innovation in teaching history. Before introducing new knowledge, teachers can test previous lesson' contents. For example, in lesson 1: Van Lang country (class 4), to examine students' knowledge and introducing new lesson, teachers can use the following mind map: Can you please complete this mind map?

Level 1: Teachers create missing or vacant mind maps and students must finish them as homework.

Level 2: Teachers ask normal questions, but students have to answer by mind map.

Level 3: Teachers require students to self-create mind map for lesson' contents as homework.

In conclusion, using mind map in teaching history is necessary and essential. Teachers can apply in every step and activity from introducing, training new knowledge to reinforcing and examining students' results to exploit this tool. As a result, applying mind map in teaching history is one of effective methods to increase the quality of teaching and learning history.

\section{Discussions from pedagogical experiments}

In to check the ability of using mind map in teaching history in primary schools, the authors experiment this activity in 1 primary class. Via observing and interviewing, students show that they like and be interested in learning history with mind map. They 
receive knowledge systematically, remember knowledge quickly and deeply. As such, students not only learn History by reading and they can self-study effectively.

However, in fact many students receive knowledge lowly. We suggest that teachers need to understand the situation of class, students' ability to instruct, support them to use mind map in different levels, and then increase their ability of using mind map gradually.

Many teachers respond that they will apply mind map in teaching history as they only instruct students to self-study and find knowledge. As such, teachers reduce their presentation and students are still interest in learning to understand knowledge systematically. They not only receive isolated information but also understand their connection.

From the above discussions, we conclude that applying mind map in teaching History in primary schools is necessary, suitable with logic and system of History program in primary schools.

\section{CONCLUSION}

Applying mind map in teaching History is an effective method to reflect structure of a historical event and phenomenon systematically in the chain of

\section{REFERENCES}

Buran, A., \& Filyukov, A. (2015). Mind mapping technique in language learning. Procedia-Social and Behavioral Sciences, 206, 215-218.

Buzan, T., \& Buzan, B. (2006). The mind map book: Pearson Education.

Central Committee of the Communist Party of Vietnam. (2013). Resolution 29-NQ/TW dated November 4, 2013, on basic and comprehensive renovation of education an training, meeting the requirements of industrialization and modernization in the conditons of a socialist-oriented market economy and international integration.

Dhiyauddin, A., Ahmad, S., Ismail, M., \& Diah, N. M. (2018). Mind mapping Approach in Learning History. International Journal of Engineering \& Technology, 7(3.15), 59-62.

Dushkova, M., \& Tsankov, S. (2015). The use of mind maps in teaching literature with the aid of information tehnologies. Paper presented at the EDULEARN15-The 7th International Conference on Education and New Learning Technologies.

Idris, S., \& Kamaruddin, N. (2018). The Effectiveness Use of Mind Maps in the Learning of History. International Journal of INTI ISSN: 01265822 Volume 22, Special Issue, December 2018. different historical events. There are few conditions to create mind map such as the number of historical factors, the connection between those factors. Teachers have to organize historical factors in relative order, and using them respectively from clarifying basic knowledge, coding knowledge, to creating shape for mind map and finally checking the ability of mind map.

Teachers can use mind map in many steps in teaching history, from creating problem-having situation at the introducing step to training new knowledge and reinforcing lesson' content at the end of class. With specific characteristic of History subject, mind map is applied in many steps (introducing, training, reinforcing, examining) to help students to understand historical events, create historical symbols, definition, and conclude experience. However, teachers need to consider mind map as one of teaching methods and it cannot replace all other teaching ways. Therefore, teachers cannot use mind map separately but in a co-operation with other methods and technics, especially problem-solving method, or applying IT in teaching history. The result is better as teachers use those teaching methods suitably and effectively. And as the quality of historical lessons increases, the quality of teaching history improves.

Le, T. L. A., \& Nguyen, T. P. (2016). Using mind map in teaching Storytelling in class 3, Journal of Education vol. 392, no. 2- 10/2016.

Li, V. G., Tran, T. C., \& Le, T. H. (2016). Building lessons in Physics under the direction of training and improving students' self-study with support of mind map, Journal of Education, vol. 395, no. 1.

Nguyen, P. L., \& Pham, H. G. (2018). The usage of mind map in teaching geography in high school Journal of Education, Special Issues, 243-246; 250.

Phan, N. L., Trinh, D. T., \& Nguyen, T. C. (2009). Historical teaching methods (2 volumes). College of Education Publishing House, Hanoi, Vietnam

Phan, T. T. N. (2014). The ability of using mind map in teaching Vietnamese perform. Journal of Education, vol. 348, no. 2.

Rudnik, Y. (2014). Methodology of" Mind maps" technology usage at primary school's foreign language lessons. Pedagogy and Psychology, 17.

Sari, R. M., Sumarmi, S., Utomo, D. H., \& Astina, I. K. (2019). Geography Teachers Perception on the Implementation of Mind Map on Scientific Approach. Paper presented at the 1st International Conference on Social Knowledge Sciences and Education (ICSKSE 2018).

Stankovic, N., Besic, C., Papic, M., \& Aleksic, V. (2011). The evaluation of using mind maps in 
teaching. Technics technologies education management, 6(2), 337-343.

Tanriseven, I. (2014). A tool that can be effective in the self-regulated learning of pre-service teachers: The mind map. Australian Journal of Teacher Education, 39(1), 5.

Tran, D. C., \& Dang, T. T. T. (2011). Teaching Learning well in primary school by mind map. Educational Publisher.
Tran, T. Y. (2020). Applying mind map in teaching English grammar for students in class 10. Journal of Science and Technology, Thai Nguyen University.

Willis, C. L., \& Miertschin, S. L. (2006). Mind maps as active learning tools. Journal of computing sciences in colleges, 21(4), 266-272.

Website: images, icons Source: https://www.flaticon.com; https://www.freepik.com 